\title{
Hierarchical Specification of Pruriceptors by Runt-Domain Transcription Factor Runx1
}

\author{
니 Qu ${ }^{1,5 *}$ Chengcheng Huang, ${ }^{2 \star}$ Xiaohua Wu, ${ }^{1}$ ○Yeqi Tao, ${ }^{1}$ Jingjing Yan, ${ }^{1}$ Tianyong Shi, ${ }^{1}$ Cheng Cao, ${ }^{2}$ Lu Han, ${ }^{1}$ \\ Mengsheng Qiu, ${ }^{1,5}$ Qiufu Ma, ${ }^{3,4}{ }^{-}$Zijing Liu, ${ }^{2}$ and ${ }^{\circ}$ Yang Liu $^{1}$ \\ 'Zhejiang Key Laboratory of Organ Development and Regeneration, Institute of Life Sciences, Hangzhou Normal University, Hangzhou 310036, People's \\ Republic of China, ${ }^{2}$ Beijing Institute of Biotechnology, Beijing 100850, People's Republic of China, ${ }^{3}$ Dana-Farber Cancer Institute and ${ }^{4}$ Department of \\ Neurobiology, Harvard Medical School, Boston, Massachusetts 02115, and ${ }^{5}$ College of Life Sciences, Zhejiang University, Hangzhou 310058, People's \\ Republic of China
}

The somatic sensory neurons in dorsal root ganglia (DRG) detect and transmit a diverse array of sensory modalities, such as pain, itch, cold, warm, touch, and others. Recent genetic and single-cell RNA sequencing studies have revealed a group of DRG neurons that could be particularly relevant for acute and chronic itch information transmission. They express the natriuretic peptide type B (NPPB), as well as a cohort of receptors and neuropeptides that have been implicated in chronic itch manifestation, including the interleukin-31 receptor A (IL-31ra) and its coreceptor oncostatin M receptor (Osmr), the cysteinyl leukotriene receptor 2 (Cysltr2), somatostatin, and neurotensin. However, how these neurons are generated during development remains unclear. Here we report that Runxl is required to establish all these molecular features of NPPB ${ }^{+}$ neurons. We further show that while early embryonic Runx 1 activity is required for the formation of NPPB ${ }^{+}$cells, at later stages Runx1 switches to a genetic repressor and thus its downregulation becomes a prerequisite for the proper development of these pruriceptors. This mode by Runx1 is analogous to that in controlling another group of pruriceptors that specifically express the chloroquine receptor MrgprA3. Finally, behavioral studies using both sexes of mice revealed marked deficits in processing acute and chronic itch in Runxl conditional knock-out mice, possibly attributable to impaired development of various pruriceptors.

Key words: chronic itch; development; NPPB; pruriceptor; Runx1; transcriptional regulation

\section{Significance Statement}

Our studies reveal a generalized control mode by Runxl for pruriceptor development and consolidate a hierarchical control mechanism for the formation of sensory neurons transmitting distinct modalities. Among dorsal root ganglion neurons that initially express the neurotrophin receptor TrkA, Runxl is necessary for the proper development of those neurons that innervate tissues derived from the ectoderm such as skin epidermis and hair follicles. These Runx1-dependent cutaneous sensory neurons are then divided into two groups based on persistent or transient Runxl expression. The Runxl-persistent group is involved in transmitting mechanical and thermal information, whereas the Runxl-transient group transmits pruriceptive information. Such hierarchical control mechanisms may provide a developmental solution for the formation of sensory circuits that transmit distinct modalities.

\section{Introduction}

The somatosensory neurons in dorsal root ganglia (DRG) detect and transmit distinct modalities of sensory information, such as

Received Jan. 11, 2017; revised April 11, 2017; accepted April 26, 2017.

Author contributions: Q.M., Z.L., and Y.L. designed research; L.Q., C.H., X.W., Y.T., J.Y., T.S., C.C., L.H., and Y.L. performed research; L.Q., C.H., Y.T., M.Q., Z.L., and Y.L. analyzed data; Q.M., Z.L., and Y.L. wrote the paper

Work performed in the laboratory of Z.L. was supported by the National Natural Science Foundation of China (Grant 31371102). Work performed in the laboratory of Y.L. was supported by the National Natural Science Foundation of China (Grants 31171071 and 31671093) and Research Foundation for Advanced Talents from Hangzhou Normal University. We thank Nancy Speck and Gary Gilliland for the floxed Runx1 mice, Rohini Kuner for the SNS/ Nav1.8-Cre mice, Tsukasa 0kuda for the Runx1- $\Delta 446$ mice, the Allen Brain Institute and The Jackson Laboratory for the Rosa26 $6^{\text {LL-tdTomato }}$ mice, and the Intellectual and Developmental Disabilities Research Center Mouse Gene Manipulation Core at Boston Children's Hospital for the generation of Rosa $26^{\text {LLL-Runx } 7}$ mice.

*L.Q. and C.H. contributed equally to this work. pain, itch, cold, warm, and touch, and their individual subtypes can be determined by differential expression of molecular markers. Three molecularly defined DRG neuron subtypes have been implicated in pruritogen-evoked itch sensation (Liu et al., 2009, 2012; Han et al., 2013; Mishra and Hoon, 2013; Stantcheva et al., 2016), and their molecular profiles have been revealed by recent large-scale single-cell RNA sequencing (Chiu et al., 2014; Usoskin

\footnotetext{
The authors declare no competing financial interests.
}

Correspondence should be addressed to either of the following: Zijing Liu, East Building, Room 847, 27 Taiping Road, Haidian District, Beijing, People's Republic ofChina, E-mail: zijingsy@yahoo.com; or Yang Liu, 16 Xuelin Street, Hangzhou, Zhejiang Province 310036, People's Republic of China, E-mail: Yang_Liu@idrbio.org.

DOI:10.1523/JNEUROSCI.0094-17.2017

Copyright $@ 2017$ the authors $\quad 0270-6474 / 17 / 375549-13 \$ 15.00 / 0$ 
et al., 2015; Li et al., 2016). Neurons expressing the G-proteincoupled receptor MrgprD (MAS-related GPR family member D), referred to as the NP1 or C5/C6 clusters of DRG neurons (Usoskin et al., 2015; Li et al., 2016), transmit a specific form of chemical itch evoked by $\beta$-alanine, although a major function of these neurons is to transmit light punctate mechanical information (Cavanaugh et al., 2009; Rau et al., 2009; Liu et al., 2012). Neurons expressing MrgprA3 (MAS-related GPR family member A3), referred to as the NP2 or C4 cluster of DRG neurons, are dedicated to itch (Liu et al., 2009; Han et al., 2013; Usoskin et al., 2015; Li et al., 2016). Ablation of NP2 neurons markedly reduces scratching responses to a range of chemical agents while retaining pain sensitivity (Han et al., 2013). The third subtype, referred to as the NP3 or C2 cluster of DRG neurons (Usoskin et al., 2015; Li et al., 2016), also emerges to play a crucial role for the transmission of itch information. These NP3 neurons are labeled by the expression of natriuretic peptide type $\mathrm{B}$ (NPPB), which serves as a neurotransmitter to signal itch information to spinal cord relay neurons (Mishra and Hoon, 2013; Usoskin et al., 2015). Removal of the $N P P B$ gene causes almost complete loss of behavioral responses to a range of itch-inducing agents (Mishra and Hoon, 2013). Thus, and surprisingly, inputs from two nonoverlapped populations of pruriceptors, NP2 and NP3, are jointly required to transmit itch evoked by many common pruritogens (Han et al., 2013; Mishra and Hoon, 2013; Usoskin et al., 2015).

In addition, NP3 neurons specifically express the interleukin-31 receptor A (IL-31ra) and its coreceptor oncostatin $\mathrm{M}$ receptor (Osmr), as well as the cysteinyl leukotriene receptor 2 (Cysltr2), all of which have been implicated in chronic allergic itch manifestation (Dillon et al., 2004; Taylor-Clark et al., 2008; Usoskin et al., 2015). Furthermore, NP3 neurons express several other neuropeptides and peptide receptors, such as somatostatin (Sst), neurotensin (Nts), and the neuropeptide Y receptor Y2 (Npy2r; Usoskin et al., 2015; Li et al., 2016). Sst-Cre marks a subset of NP3 neurons, and their ablation causes a reduction of scratching behavior evoked by interleukin-31 (Stantcheva et al., 2016), further consolidating a role for NP3 neurons in transmitting both acute itch and possibly chronic itch as well.

A major question in developmental neurobiology is to understand how these somatic sensory neuron subtypes are specified and segregated during development. We have reported previously that the runt-domain transcription factor Runx1 is necessary for the specification of $\mathrm{MrgprD}^{+} \mathrm{NP} 1$ and MrgprA3 ${ }^{+} \mathrm{NP} 2$ neurons (Chen et al., 2006; Liu et al., 2008; Lou et al., 2013) as well as several other classes of sensory neurons associated with the transmission of thermal and mechanical information (see Fig. 7, summary). Here, we performed both loss-of-function and gainof-function studies, showing that Runxl is required to establish a unique molecular program associated with $\mathrm{NPPB}^{+} \mathrm{NP} 3$ neurons. Our studies also reveal a generalized hierarchical control mechanism that allows pruriceptors to be segregated from other sensory modalities.

\section{Materials and Methods}

Animals. The generation of mice carrying the floxed Runxl allele (RRID: MGI:4358522), Wnt1-Cre and SNS-Cre transgenic mice, has been described previously (Jiang et al., 2000; Agarwal et al., 2004; Growney et al., 2005). Rosa $26^{\text {LSL-tdTomato }}$ mice were purchased from The Jackson Laboratory. The morning that vaginal plugs were observed was considered embryonic day 0.5 (E0.5). For immunohistochemical studies, mice at postnatal day 30 (P30) were used. For behavioral analyses, 1- to 2-month-old mutant and control littermates of either sex were used. All behavioral test protocols were approved by the Institutional Animal Care and Use Committee at Hangzhou Normal University.
Generation of Runx1 conditional knock-in mice. To target the Rosa26 locus, the Rosa26 acceptor was constructed, which contained a CAGLoxp-PGK-Neo-poly(A)-Loxp cassette flanked with 5' and 3' homology arms, as well as a diphtheria toxin cassette for negative selection. The cDNA containing a complete open reading frame of Runxl was then inserted between the second Loxp site and the 3' homology arm. The final targeting vector was linearized and electroporated into the $129 \mathrm{~Sv} / \mathrm{J}$ J1 ES cell line. G418-resistant ES cell clones were selected and screened by Southern hybridization. Genomic DNA digested with EcoRV was analyzed with a $0.7 \mathrm{~kb}$ probe (immediately upstream of the $5^{\prime} \mathrm{arm}$ ). Chimeric mice were generated from positive ES cell clones following standard procedures. By mating with C57BL/6J mice, the germline transmission was obtained and confirmed by both Southern blot and PCR. The genotyping PCR was performed using the following set of primers: $5^{\prime}$-GAG TTC TCT GCT GCC TCC TGG-3' ${ }^{\prime}$ 5' -CGA GGG CAG CCA TAG CAA CTC-3' , and 5' -CGA GGC GGA TCA CAA GCA ATA-3', with wild-type allele showing a 300 bp band and the Runx1 knock-in allele showing a $600 \mathrm{bp}$ band by agarose gel electrophoresis.

In situ hybridization and immunofluorescence. Mice were anesthetized with $\mathrm{CO}_{2}$ and perfused with $4 \%$ paraformaldehyde in $\mathrm{PBS}, \mathrm{pH}$ 7.4, at $4^{\circ} \mathrm{C}$. Spinal cords and DRG were dissected and postfixed at $4^{\circ} \mathrm{C}$ for $16-18$ h. Tissues were cryoprotected in $25 \%$ sucrose, embedded with O.C.T., and stored at $-80^{\circ} \mathrm{C}$ before use. The procedures for in situ hybridization (ISH) and probe preparation have been described previously (Chen et al., 2006). The primer information for preparing all probes was from http:// www.brain-map.org. The primary antibodies used in immunofluorescence (IF) staining include rabbit anti-Runx1 monoclonal antibody (1: 500; catalog \#ab92336, Abcam RRID:AB_2049267) and rabbit anti-c-Fos (1:1000; catalog \#ABE457, Millipore; RRID:AB_2631318). FITC-conjugated Isolectin B4 (IB4) was purchased from Sigma-Aldrich. The secondary antibodies were from Life Technologies. The ISH/IF double staining was performed as previously described (Liu et al., 2008).

Behavioral studies. All itch behavioral tests were performed as previously described with minor modifications (Shimada and LaMotte, 2008; Liu et al., 2010). Briefly, pruritic compounds were subcutaneously injected into the nape of the neck, or the left cheek of the animal for the cheek injection, after animal acclimatization. Both males and females mice were used for the studies. For the allergy itch model, $50 \mu \mathrm{g}$ of ovalbumin and $2 \mathrm{mg}$ of Inject Alum dissolved in PBS were administered intraperitoneally twice, separated by $10 \mathrm{~d}$. One week after the second sensitization, $50 \mu \mathrm{g}$ of ovalbumin was injected to monitor itch responses. Behavioral responses were recorded for $30 \mathrm{~min}$, and the video was replayed to count the number of scratching bouts with the hindpaw directed toward the injection site. Investigators who performed these behavioral analyses are blinded to genotypes.

c-Fos induction in the spinal cord. One- to two-month-old Runx $1^{F / F}$; Wht1-Cre and Runx $1^{F / F}$ mice were anesthetized with isoflurane. Eighteen micrograms of IL-31 in $10 \mu \mathrm{l}$ of saline was injected into the left planta. Two hours later, the L4-L5 spinal cords were dissected and treated as previously described (Liu et al., 2010). Frozen spinal cord sections $(14 \mu \mathrm{m})$ were immunostained for c-Fos according to the manufacturer instructions.

Cell counting and statistical analysis. L4 or L5 lumbar DRG were dissected from two to three pairs of mutant and control mice. Three to four mutant or control DRG were used to prepare six sets of adjacent sections at $12 \mu \mathrm{m}$ thickness. Each set was processed for immunostaining or was used for ISH with the probe of the gene of interest. The data obtained with a Superior Cervical Ganglion 10 (SCG10) probe were presented as the total number of neurons on one set of sections, and that of other probes were normalized accordingly. Only cells containing nuclei and showing levels of expression or staining clearly above background were counted. Representative data are from experiments that were replicated biologically at least three times with similar results. For itching behavioral tests, averages and SEMs of scratching bouts were calculated for each group, and the difference between control and mutant samples was subjected to a two-tailed, unpaired Student's $t$ test, with $p<0.05$ considered to be significant. To determine the Runxl expression level, 8 bit grayscale images of DRG sections stained with Runx1 antibody and a fluorescence-conjugated secondary antibody were analyzed using Image) 


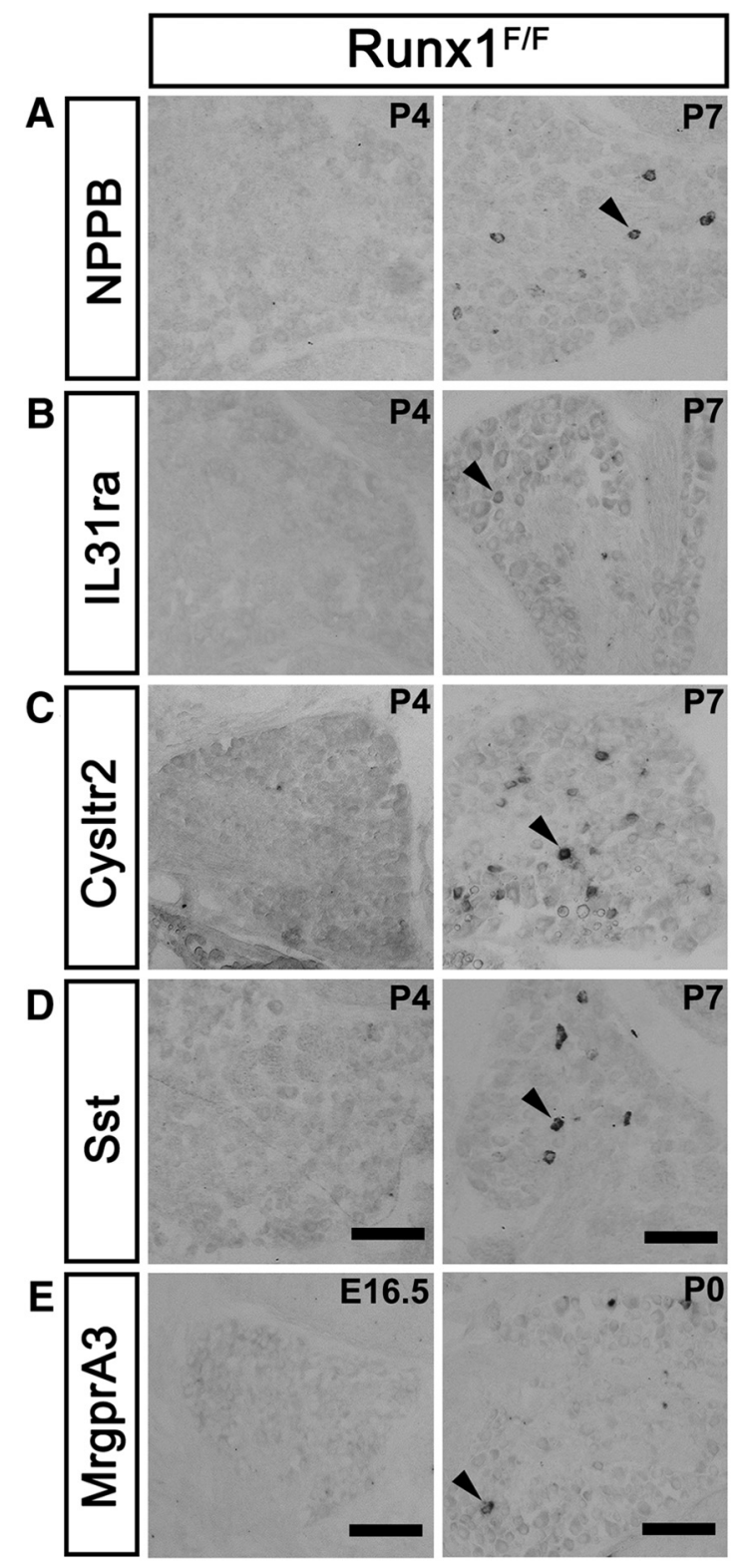

Figure 1. Developmental onset of NP3 and NP2 markers in DRG. $A-E$, ISH with indicated probes of NP3 markers, including NPPB ( $\boldsymbol{A})$, IL-31ra ( $\boldsymbol{B})$, Cyslttr2 (C), and somatostatin (Sst) (D), and NP2 marker $\operatorname{MrgprA3}(\boldsymbol{E})$ were performed on sections through lumbar DRG from Runx $7^{\mathrm{F} / \mathrm{F}}$ control mice atindicated developmental stages. Arrowheads indicate positive cells. Scale bars, $50 \mu \mathrm{m}$.

(RRID:SCR_003070) and Adobe Photoshop (RRID:SCR_014199). The images were inverted, and the average grayscales ( $\mathrm{K}$ value) of signals in individual nuclei were measured for all cells within a given DRG section. The highest density of Runx 1 signal was set as $100 \%$, and the relative intensity of signal (RIS) in other cells was calculated. The normalized RIS was used to categorize the differential expression level of Runx1. $\chi^{2}$ tests were performed using SPSS (RRID:SCR_002865), with $p<0.05$ considered to be significant.

\section{Results}

Impaired development of $\mathrm{NPPB}^{+} \mathrm{NP} 3$ pruriceptors in Runx1 conditional knock-out mice

We first used ISH to examine the expression patterns of NP3 markers in wild-type DRG at different developmental stages. We found that NPPB expression was initiated at P7 $(6.4 \pm 0.6 \%$ of total DRG neurons) in lumbar DRG (Fig. $1 A$ ), the extent of which peaked at P10 (10.2 \pm 0.5\%; data not shown) and remained stable at young adult stages (P30; $11.4 \pm 0.9 \%$; Fig. 2A, left). Similarly, the expression of IL-31ra, Cysltr2, and Sst in DRG emerged at P7 and was also detectable at P30 (Figs. $1 B-D$, $2 B, D, F$, left panels). The synchronized onset of these NP3 neuron markers suggested the existence of a selector-like transcriptional program that coordinates NP3 neuron development. In contrast to the relatively late onset of NP3 neuron markers, expression of the NP1 marker MrgprD was initiated at E16 and the expression of the NP2 marker MrgprA3 started at P0 (Fig. 1E; Chen et al., 2006; Abdel Samad et al., 2010).

We reported previously that the runt domain transcription factor Runx1 is necessary for the development of NP1 and NP2 neurons (Chen et al., 2006; Liu et al., 2008). To determine whether Runx1 was involved with the specification of NP3 neurons, we generated Runxl conditional knock-out (CKO) mice by crossing Run $x 1^{F / F}$ mice with Wnt1-Cre. In the resulting Runx $1^{F / F}$; Wnt1-Cre mice, Runx1 was removed in all neural crest cells including sensory precursors (Jiang et al., 2000; Chen et al., 2006). We next performed ISH and found that the expression of NP3 markers, including NPPB, IL-31ra, Osmr, Cysltr2, Npy2r, Sst, and Nts, was all abolished in P30 DRG from Runx $1^{F / F}$; Wnt1-Cre mice (Fig. 2A-G, middle panels). As previously reported (Chen et al., 2006), the expression of NP2 marker MrgprA3 was also lost in Run $x 1^{F / F}$;Wnt1-Cre DRG (Fig. $2 \mathrm{H}$, middle), indicating that Runx1 coordinates the development of two principle populations of pruriceptors, NP2 and NP3. Regarding Npy2r, it should be noted that single-cell sequencing reveals the strong expression in NP3 neurons as well as the weak expression in myelinated neurons (Chiu et al., 2014; Usoskin et al., 2015; Li et al., 2016), and this weak expression was not detected by our ISH in P30 DRG (data not shown). A recent study shows that DRG neurons marked by the transgenic Npy2r::Cre, which are distinct from neurons labeled by transgenic Npy2r::GFP (Li et al., 2011), are required to sense pinprick-evoked mechanical pain (Arcourt et al., 2017). Development of these myelinated Npy2 $\mathrm{r}^{+}$neurons is likely independent of Runx1 since pinprick-evoked pain remains intact in Runx1 ${ }^{F / F}$;Wnt1-Cre mice (Chen et al., 2006).

To gain insight into what developmental stages Runx 1 activity is required to control NP3 neuron development, we created a different line of Runx1 CKO mice by crossing Runx $1^{F / F}$ mice with the transgenic SNS-Cre mice, in which Cre is driven from a genomic fragment derived from the $\mathrm{SNS} / \mathrm{Na}_{\mathrm{v}} 1.8$ promoter region and Cre expression starts at $\sim$ E16.5 (Agarwal et al., 2004; Abdel Samad et al., 2010). The resulting CKO mice were referred to as Run $x 1^{F / F}$;SNS-Cre. We found that the expression of NPPB, IL31ra, Osmr, Cysltr2, Npy2r, Sst, and Nts was still eliminated in Run $x 1^{F / F}$;SNS-Cre mice (Fig. $2 A-G$, right panels). Consistent with our previous report (Abdel Samad et al., 2010), the expression of the NP2 marker MrgprA3 was, however, retained in Run $x 1^{F / F}$;SNS-Cre mice (CKO, $8.5 \pm 0.1 \%$; control, $11.3 \pm 0.2 \%$; $n=3$ for each group; $p=0.15$; Fig. $2 H$, right). Thus, while Runx 1 activity before $\mathrm{E} 16.5$ is needed to establish a competent state for the specification of NP2 pruriceptors, Runx1 needs to operate beyond E16.5 to specify NP3 pruriceptors.

\section{Attenuated acute chemical itch in conditional Runx1-null mice}

Both NP2 and NP3 neurons have been implicated to play a major role in transmitting itch information (Han et al., 2013; Mishra and Hoon, 2013; Stantcheva et al., 2016). To further confirm impaired specification of these neurons in Runx $1^{F / F}$;Wnt1-Cre mice, we examined itch responses evoked by a range of chemical pruritogens. To do this, we performed intradermal injections of a 


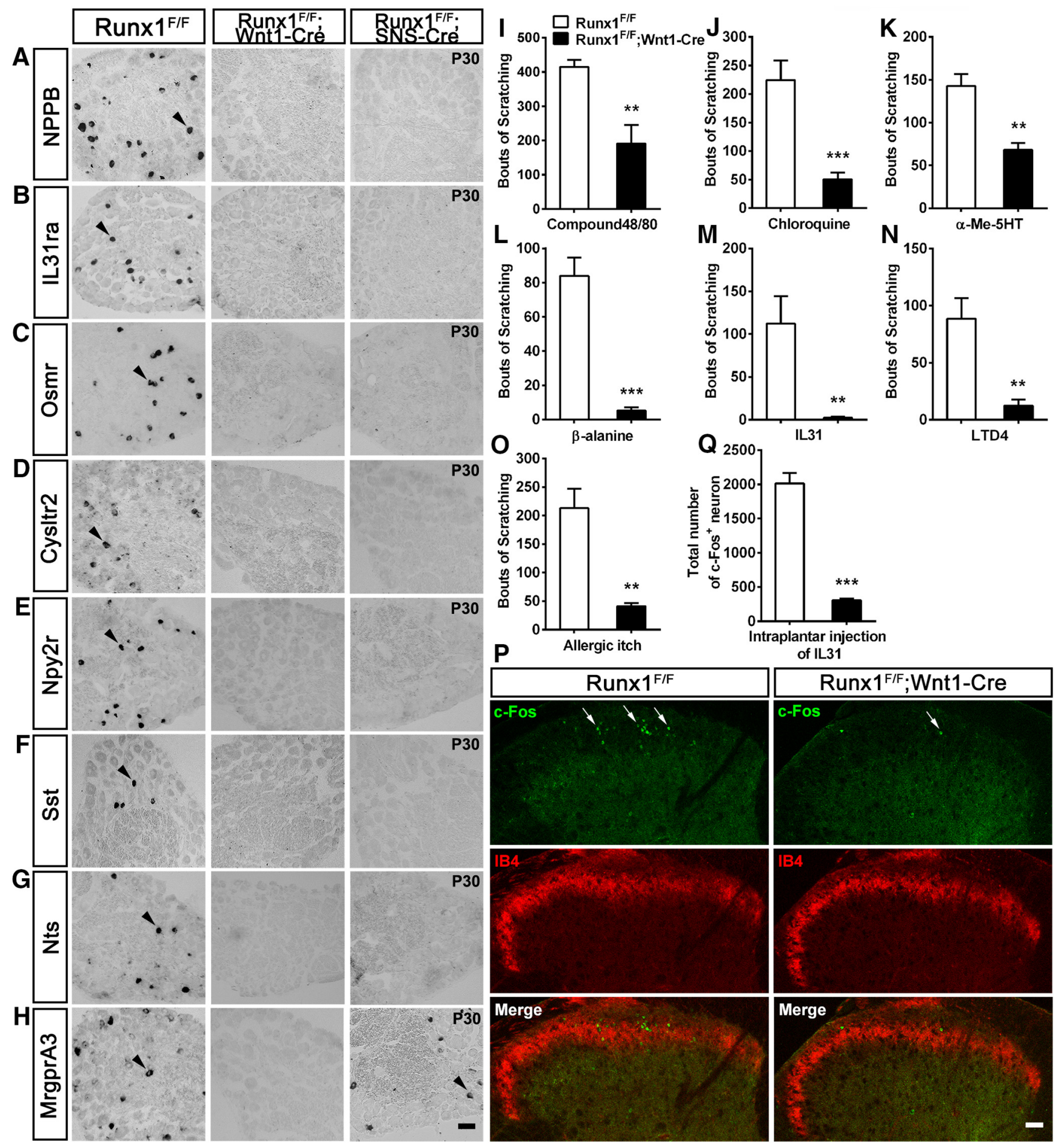

Figure 2. Impaired NP3 neuron development and diminished acute and chronic itch responses in Runx1 mutant mice. $\boldsymbol{A}-\boldsymbol{H}$, ISH with indicated probes of NP3 markers, including NPPB $(\boldsymbol{A})$, IL-31ra $(\boldsymbol{B}), 0$ smr $(\boldsymbol{C})$, Cysltr2 $(\boldsymbol{D}), \operatorname{Npy2r}(\boldsymbol{E})$, somatostatin $(\boldsymbol{F})$, and neurotensin $(\boldsymbol{G})$, and NP2 marker MrgprA3 $(\boldsymbol{H})$ were performed on sections through lumbar DRG from P30 Runx $7^{\mathrm{F} / F}$ control mice and

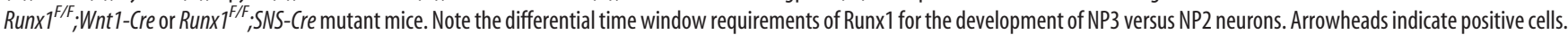
Scale bar, $50 \mu \mathrm{m} . I-\mathbf{O}$, Runx $7^{\mathrm{F} / \mathrm{F}}$;WntT-Cre mice (column in black) exhibited remarkable scratching defects after intradermal injection of Compound $48 / 80(n=4 ; I), C Q(n=7 ; J), \alpha$-Me-5HT $(n=$ $4 ; \boldsymbol{K}), \beta$-alanine $(n=5 ; \boldsymbol{L}), \mathrm{IL}-31(n=5 ; \boldsymbol{M})$, and LTD4 $(n=5 ; \boldsymbol{N})$, and diminished allergic chronic itch responses in an ovalbumin-induced allergic itch model $(n=5 ; \boldsymbol{O})$ compared with $R$ unx $^{F^{F / F}}$ control mice (column in white). Error bars represent the SEM. Significant differences were determined by using Student's test: ${ }^{* *} p<0.01,{ }^{* * *} p<0.001 . P, \mathbf{Q}$, Double stainings with c-Fos antibody and Isolectin B4 were performed on sections through $\mathrm{L} 4-\mathrm{L} 5$ spinal cord from adult RunX $7^{\mathrm{F} / F}$; Wnt1-Cre and Runx $7^{\mathrm{F} / \mathrm{F}}$ control mice pretreated with intraplantar injection of IL-31. Significantly reduced c-Fos signals (arraw) in the superficial dorsal horn from Runx $7^{\mathrm{F} / F}$;Wnt1-Cre mice suggested impaired itch sensitivity in Runx1 mutant mice. Scale bar, $50 \mu \mathrm{m}$.

series of pruritogenic agents into the nape region and recorded the scratching responses. We found that scratching bouts evoked by Compound $48 / 80$, an agent indirectly activating histaminedependent itch pathway (Sugimoto et al., 1998), were reduced in
Run $x 1^{F / F}$;Wnt1-Cre CKO mice in comparison with Run $x 1^{F / F}$ control mice (CKO, $191 \pm 54$; control, $415 \pm 21 ; n=4$ for both groups; $p=0.0085$; Fig. $2 I)$. Chloroquine (CQ) evokes histamine-independent itch (Liu et al., 2009). In Runx1 ${ }^{F / F} ;$ Wnt1-Cre 
CKO mice, CQ-evoked scratching responses were dramatically diminished (CKO, $50 \pm 12$; control, $224 \pm 34 ; n=7$ for both groups; $p=0.0005$; Fig. $2 J)$. In addition, the injection of $\alpha$-methyl-serotonin ( $\alpha$-Me-5HT), a serotonin derivative (Imamachi et al., 2009), elicited reduced scratching in Runx1 ${ }^{F / F}$;Wnt1-Cre mice ( $68 \pm 8$ bouts) compared with that in control littermates (143 \pm 14 bouts; $n=4$ for both groups, $p=0.0034$; Fig. $2 K$ ). Similarly, intradermal injection of $\beta$-alanine in the cheek evoked robust scratching responses in control mice, but nearly none in $R u n x 1^{F / F}$; Wnt1-Cre mice (CKO, $5.2 \pm 2.0$; control, $84 \pm 11 ; n=5$ for each group; $p=0.00008$; Fig. $2 L$ ), attributable to the loss of its receptor MrgprD, a marker for NP1 cells (Liu et al., 2012; Usoskin et al., 2015). These data indicated that acute itch sensitivity to multiple pruritogens is attenuated or virtually abolished following the constitutive loss of Runx1 function in developing DRG neurons.

\section{Impaired chronic itch in conditional Runx1-null mice}

IL-31 and leukotriene D4 (LTD4) are two endogenous mediators associated with chronic inflammatory itch through the receptors IL-31ra/Osmr and Cysltr2, respectively (Dillon et al., 2004; Taylor-Clark et al., 2008). Strikingly, the injection of IL-31 and LTD4 scarcely induced an itching response in $R u n \times 1^{F / F}$; Wnt1Cre CKO mice (IL-31: $2.3 \pm 1.3$ in CKO vs $112 \pm 32$ in control, $n=5$ for both groups, $p=0.009$; LTD $4: 12 \pm 5$ in CKO vs $89 \pm$ 18 in control, $n=5$ for both groups, $p=0.0037$; Fig. $2 M, N)$, which is coincident with the loss of IL-31ra and Cysltr2 expression in DRG from Runx1 $1^{F / F}$;Wnt1-Cre mice. We next analyzed the chronic itch responses in Runx $1^{F / F}$;Wnt1-Cre mice. In a mouse model of ovalbumin-induced allergic itch (Krajnik and Zylicz, 2001), we found that the spontaneous scratching bouts were dramatically reduced in $R u n x 1^{F / F}$;Wnt1-Cre mice $(41 \pm 6$ bouts), compared with that in $R u n x 1^{F / F}$ control mice (212 \pm 34 bouts; $n=5$ for both groups; $p=0.004$; Fig. 2O), suggesting that, in addition to acute chemical itch, chronic allergic itch sensitivity is also greatly attenuated in the absence of Runx1.

\section{Impaired itch information transmission in the spinal cord of conditional Runx1-null mice}

Using c-Fos expression as a marker for the activation of spinal neurons (Hunt et al., 1987; Gao and Ji, 2009), we next examined itch information transmission from the skin to the spinal cord. In Runx $1^{F / F}$ control mice, intraplantar injection of IL-31 induced robust c-Fos expression in Laminar II of the ipsilateral dorsal spinal cord (Fig. $2 P$, left). In the spinal segment innervated by L4 and L5 DRG neurons, $2013 \pm 149 \mathrm{c}-F o s^{+}$neurons were detected. In contrast, only $307 \pm 26 \mathrm{c}-\mathrm{Fos}^{+}$neurons were observed in the L4-L5 segment of the spinal cord from Runx $1^{F / F}$;Wnt1-Cre mice (Fig. $2 P$, right), representing an $85 \%$ reduction $(n=3$ for both groups; $p=0.00035$; Fig. $2 Q$ ). Thus, consistent with marked behavioral deficits, transmission of itching information from the skin to the spinal cord is compromised in Run $x 1^{F / F}$;Wnt1-Cre mice.

\section{Transient Runx1 expression in $\mathrm{NPPB}^{+} \mathrm{NP} 3$ neurons}

We next examined how Runx1 controls NP3 neuron development. We reported previously that Runx1 uses two distinct modes in controlling the development of $\mathrm{MrgprD}^{+} \mathrm{NP} 1$ and MrgprA3 ${ }^{+}$NP2 neurons (Liu et al., 2008; Usoskin et al., 2015). Runx1 is genetically a constitutive activator for MrgprD, and, accordingly, Runx1 expression is persistent in most MrgprD ${ }^{+}$ NP1 neurons (Liu et al., 2008), as also shown below. In contrast, Runx1 switches from an activator at early embryonic stages to a repressor at postnatal stages (in genetic terms) in regulating MrgprA3 expression. As such, Runx1 expression needs to be downregulated in prospective MrgprA3 ${ }^{+}$NP2 neurons before MrgprA3 expression is established at neonatal stages (Liu et al., 2008). To determine what mode is used by Runx1 to control NP3 neuron development, we examined Runxl expression patterns in developing $\mathrm{NPPB}^{+} \mathrm{NP} 3$ neurons using double staining of Runx1 protein and NPPB mRNA and then compared the results with Runx1 expression in MrgprD ${ }^{+}$NP1 and MrgprA3 ${ }^{+}$NP2 cells. We first confirmed the specificity of the rabbit anti-Runx1 monoclonal antibody by showing the complete loss of Runx1 immunostaining signals in the nuclei of DRG neurons from $R u n x 1^{F / F}$; Wnt1-Cre mice (Fig. 3A). Because of variable Runx1 expression levels from cells to cells, we determined the RIS for all individual cells within a given DRG section. We found the following three major categories of Runxl expression: (1) negative (RIS $<20 \%$ for barely detectable expression); (2) low (with RIS within the range of $20 \%$ to $60 \%$ ); and (3) high (with RIS $>60 \%$ ). $\mathrm{NPPB}^{+}$ NP3 neurons largely display negative or low levels of Runx1 expression at every stage examined, including P7, when NPPB expression is initiated (negative, 25.7\%; low, 72.1\%; high, 2.2\%; Fig. $3 B, F$ ), and P30 (negative, 22.6\%; low, 74.0\%; high, $3.4 \%$; Fig. $3 C, G)$. MrgprA3 ${ }^{+} \mathrm{NP} 2$ neurons also show negative and low levels of Runx1 expression (negative, 73.4\%; low, 26.2\%; high, $0.4 \%$; Fig. $3 \mathrm{D}, \mathrm{H})$, although the negative category is more dominant $\left(73.4 \%, 204\right.$ of 278 neurons) in comparison with $\mathrm{NPPB}^{+}$ NP3 neurons (22.6\%, 47 of 208 neurons; $\chi^{2}$ test, $\left.p<0.001\right)$. In contrast, most of the MrgprD ${ }^{+} \mathrm{NP} 1$ neurons showed high levels of Runx1 expression (negative, 3.9\%; low, 36.0\%; high, 60.1\%; Fig. $3 E, I)$. The percentage of $\mathrm{MrgprD}^{+} \mathrm{NP} 1$ neurons with high Runx1 expression at $\mathrm{P} 30(60.1 \%, 668$ of 1112 neurons $)$ is significantly different from that of $\mathrm{NPPB}^{+} \mathrm{NP} 3$ neurons $(3.4 \%, 7$ of 208 neurons; $\chi^{2}$ test, $\left.p<0.001\right)$ or MrgprA3 ${ }^{+}$NP2 neurons $\left(0.4 \%, 1\right.$ of 278 neurons; $\chi^{2}$ test, $\left.p<0.001\right)$. We reported previously that at E12.5-E14.5, Runx1 is highly expressed in most, if not all, TrkA lineage sensory neurons (Chen et al., 2006), and these $\operatorname{TrkA}^{+}$neurons give rise to all small-diameter unmyelinated sensory neurons that NP1-3 cells belong to (Ma et al., 1999; Patel et al., 2000; Zylka et al., 2005; Han et al., 2013; Mishra and Hoon, 2013; Usoskin et al., 2015). Thus, Runx1 expression is either eliminated or downregulated in prospective NP2 and NP3 neurons by the time NP2/3 neuron markers are established.

\section{Genetic prevention of Runx1 downregulation impaired $\mathrm{NPPB}^{+}$neuron development}

We next asked whether the downregulation of Runx1 is necessary for the development of $\mathrm{NPPB}^{+} \mathrm{NP} 3$ neurons. To test this, we constructed a new conditional Runxl knock-in mouse line, Rosa26-lox-STOP-lox-Runx1, which is referred to as $R 26^{\text {Runx } 1}$, in which Runx1 expression is driven by the constitutive Rosa26 promoter once the "STOP" cassette is removed through Cremediated recombination (Fig. $4 A$ ). This mouse line was originally created for the purpose of studying nociceptor plasticity following nerve injury, which normally turns off Runx1 expression (data not shown). This injury-induced Runx1 extinguishment can be prevented by using the Rosa26 promoter to drive ectopic Runxl expression, whereas gene expression driven from the Tau promoter is still downregulated following nerve injury (data not shown). By crossing R26 $6^{\text {Runxl }}$ mice with SNS-Cre and $R 26^{\text {tdTomato }}$ reporter mice, we generated $R 26^{\text {Runxi/tdTomato }} ; S N S$ Cre mice, in which the expression of exogenous Runx1 and tdTomato occurred in most nociceptors with the expression of Cre recombinase driven from the SNS/Nav1.8 promoter (Agarwal et al., 2004). We found that, compared with $68.5 \pm 1.6 \%$ of tdTomato $^{+}$DRG neurons labeled by Runxl antibody in P30 

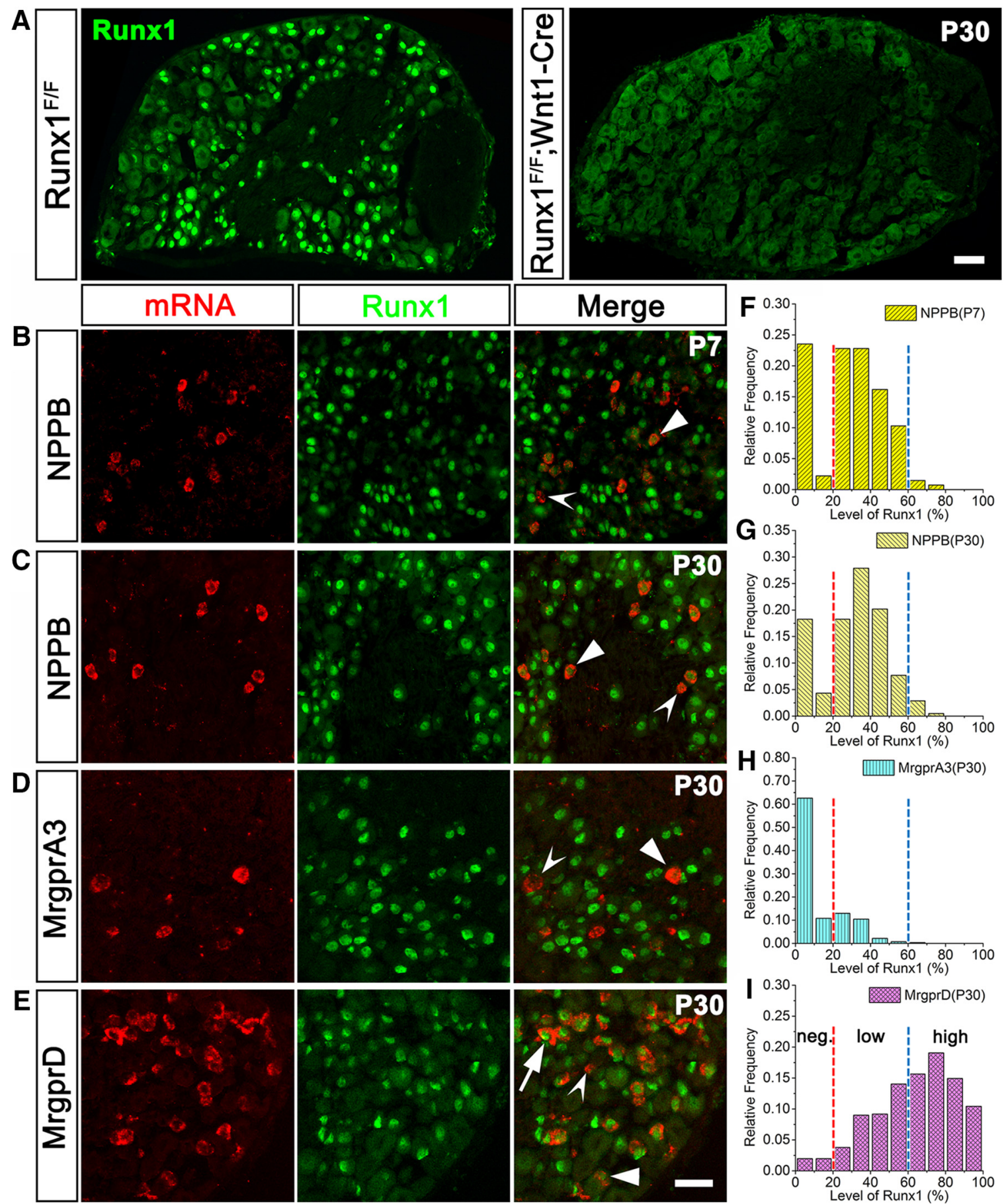

Figure 3. Runx1 expression patterns in NP1, NP2, and NP3 subtypes of DRG neurons. $A$, Immunohistocompatibility staining on DRG sections from P30 Runx $7^{F / F}$ control (left) and Runx $7^{F / F}$;Wnt1Cre (right) mice demonstrated the sensitivity and specificity of the anti-Runx1 antibody used in this study. Scale bar, $100 \mu \mathrm{m} . \boldsymbol{B}-\boldsymbol{E}$, ISH with indicated probes combined with Runx 1 immunostaining was performed on DRG sections from P7 ( $\boldsymbol{B}$ ) or P30 ( $\boldsymbol{C}-\boldsymbol{E}$ ) wild-type mice. A low level of Runx 1 expression (arrowhead) or none (sunken arrowhead) was detected in NPPB-expressing NP3 ( $\boldsymbol{B}, \boldsymbol{C}$ ) and MrgprA3-expressing NP2 (D) neurons, while most MrgprD ${ }^{+}$NP1 neurons maintained high levels of Runx1 expression ( $\boldsymbol{E}$, arrow). Scale bar, $50 \mu \mathrm{m}$. $\boldsymbol{F}-\boldsymbol{I}$, Quantification of NPPB ${ }^{+}$( $n=136$ cells for P7 and 208 cells for P30), $\operatorname{MrgprA3}^{+}\left(n=278\right.$ cells), and MrgprD ${ }^{+}(n=1112$ cells) neurons based on their relative intensity of Runx 1 signal (negative, $<20 \%$; low, 20\% to 60\%; high, $>60 \%)$.

$R 26^{+/ t d \text { Tomato }} ;$ SNS-Cre control mice, $94.8 \pm 0.6 \%$ of tdTomato DRG neurons were Runx ${ }^{+}$in P30 R26 Runxl/tdTomato ;SNS-Cre mice $(n=3$ for each group; $p=0.0004$; Fig. $4 B, C)$. Thus, Runx 1 expression became constitutive in most, if not all, SNS-Cremarked DRG neurons.

We next analyzed the phenotypes in $R 26^{\text {Runx } 1 /+}$;SNS-Cre mice. Using the pan-neuronal marker SCG10, we detected comparable total numbers of neurons on each set of L4 DRG sections between $R 26^{\text {Runxl/+ }}$ control mice $(1020 \pm 53)$ and $R 26^{\text {Runxl/+ }}$; SNS-Cre mice ( $1069 \pm 79 ; n=4$ for each group; $p=0.64$; Fig. $4 D, I)$, indicating that the expansion of Runx 1 expression in $R 26^{\text {Runxl/+}}$;SNS-Cre DRG did not cause cell death. Using adjacent sections, the counting of $\mathrm{NPPB}^{+}$and $\mathrm{IL}^{-31 \mathrm{ra}^{+}}$neurons revealed a marked reduction in $R 26^{\text {Runx } 1 /+} ;$;SN-Cre DRG (NPPB: from $13.1 \pm 1.1 \%$ in control mice to $4.7 \pm 0.3 \%$ in mutants, $n=$ 4 for each group, $p=0.0017$; IL-31ra: from $12.9 \pm 0.2 \%$ in 

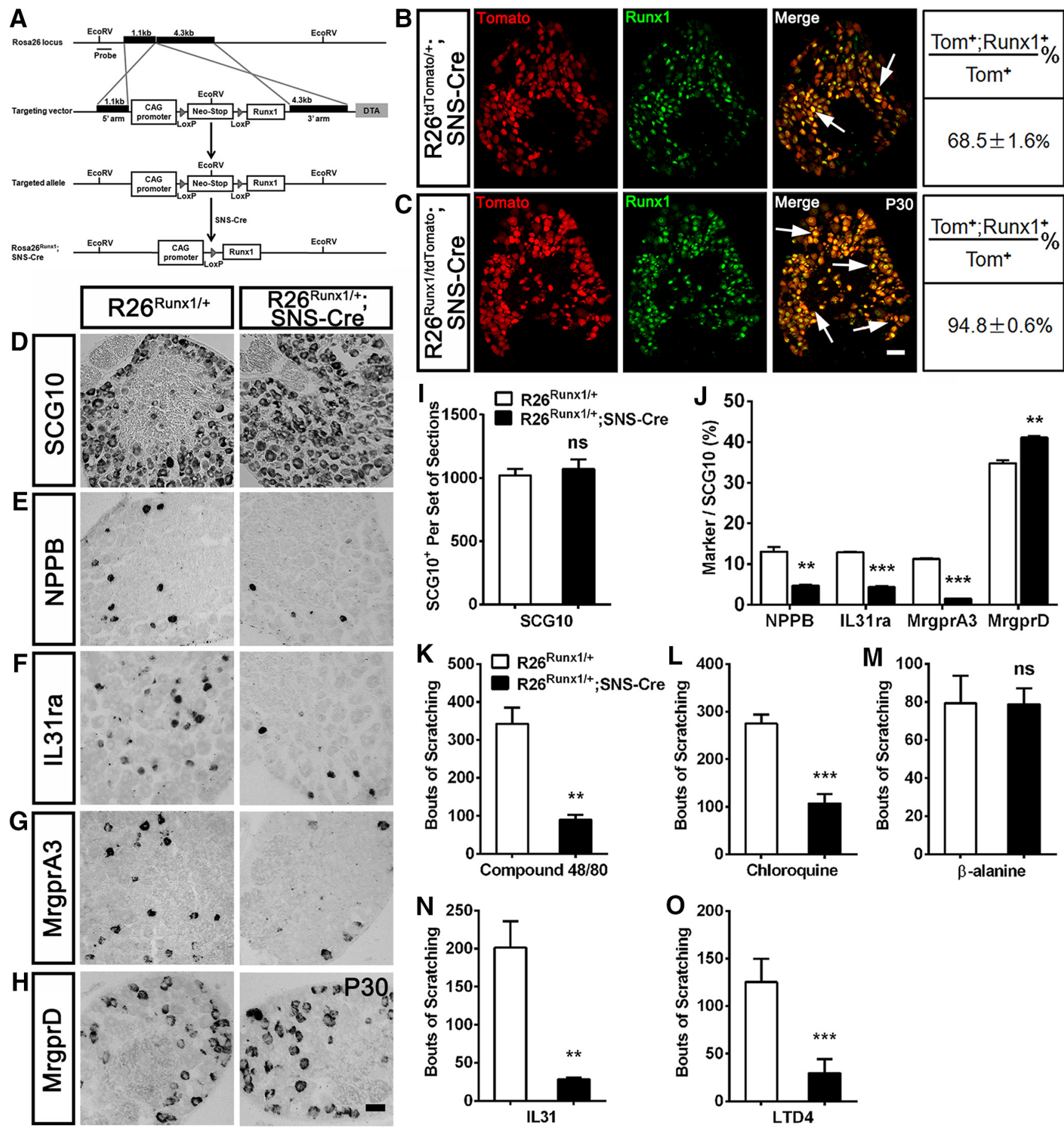

Figure 4. Compromised NP3 and NP2 pruriceptor development and impaired itch responses to pruritogens in mice with constitutive Runx1 expression in DRG. $\boldsymbol{A}$, Diagram showing the generation of a Rosa26-Loxp-STOP-Loxp-Runx 1 knock-in mouse line. The open reading frame of Runx1, following a STOP cassette (Neo) flanked by two LoxP sites, was insert into the Rosa26 locus, which could offer constitutive Runx1 expression upon removal of the STOP cassette by Cre-mediated recombination. B, C, Runx1 immunostaining on DRG sections from P30 R26 ${ }^{+/ t d T o m a t o}$;SNS-Cre control and $R 26^{\text {Runx } 1 / \text { tdTomato }}$;SNS-Cre mice and quantitative data shown to the right demonstrated the constitutive Runx1 expression in SNS-Cre-marked DRG neurons in the Runx1 gain-of-function mice used in this study. Arrows indicate Runx1 ${ }^{+} ;$;omato $^{+}$cells. Scale bar, $100 \mu \mathrm{m} . \boldsymbol{D}-\boldsymbol{H}$, ISH with indicated probes, including SCG10 (D), NPPB (E), IL-31ra $(\boldsymbol{F}), \operatorname{MrgprA3}(\boldsymbol{G})$, and MrgprD (H), was performed on sections through L4 or L5 lumbar DRG from P30 R26 Runx1/+ ;SNS-Cre and R26 Runx1/+ control mice. Note the impaired expression of NP2 and NP3 markers in the DRG with constitutive Runx1 expression. Scale bar, $50 \mu \mathrm{m} . \boldsymbol{I}, \boldsymbol{J}$, Quantification of positive cells detected by the probe of SCG10 $(\boldsymbol{I})$ and NP1-3 neuron markers $(\boldsymbol{J})$. Note that while the total number of DRG neurons remained intact, the development of NP2 and NP3 neurons was compromised in R26 Runx1/+ ;SNS-Cre mice. $\boldsymbol{K}-\mathbf{0}$, Intradermal injection of Compound 48/80 $(n=4 ; \boldsymbol{K}), \mathrm{CQ}(n=4 ; \boldsymbol{L}), \mathrm{IL}-31$ ( $n=4 ; \boldsymbol{N})$, and LTD4 $(n=$ $5 ; 0)$ induced attenuated itch responses in $R 26^{\text {Runx } 1 /+} ;$;NS-Cre mice, while $\beta$-alanine injection in the cheek caused comparable bouts of scratching $(n=5$; $\boldsymbol{M}$ ). Error bars represent the SEM. Significant differences were determined by using Student's $t$ test: ${ }^{* *} p<0.01,{ }^{* * *} p<0.001$. ns, Not significant.

control mice to $4.4 \pm 0.2 \%$ in mutants, $n=4$ for each group, $p=$ 0.0001 ; Fig. $4 E, F, J)$. Similarly, the percentage of MrgprA3 ${ }^{+} \mathrm{NP} 2$ neurons was reduced from $11.2 \pm 0.3 \%$ in control mice to $1.5 \pm$ $0.1 \%$ in $R 26^{\text {Runx } 1 /+} ;$ SNS-Cre mice $(n=4 ; p=0.0002$; Fig. $4 G, J)$.
In contrast, a statistically significant, albeit slight, increase in $\mathrm{MrgprD}^{+}$neurons was observed in $\mathrm{R}^{\text {Runxl/+;}}$ SNS-Cre mice (control mice: $34.8 \pm 0.7 \% ; R 26^{\text {Runxl/+}}$;SNS-Cre mice: $41.1 \pm$ $0.3 \% ; n=4 ; p=0.0015$; Fig. $4 H, J)$. 


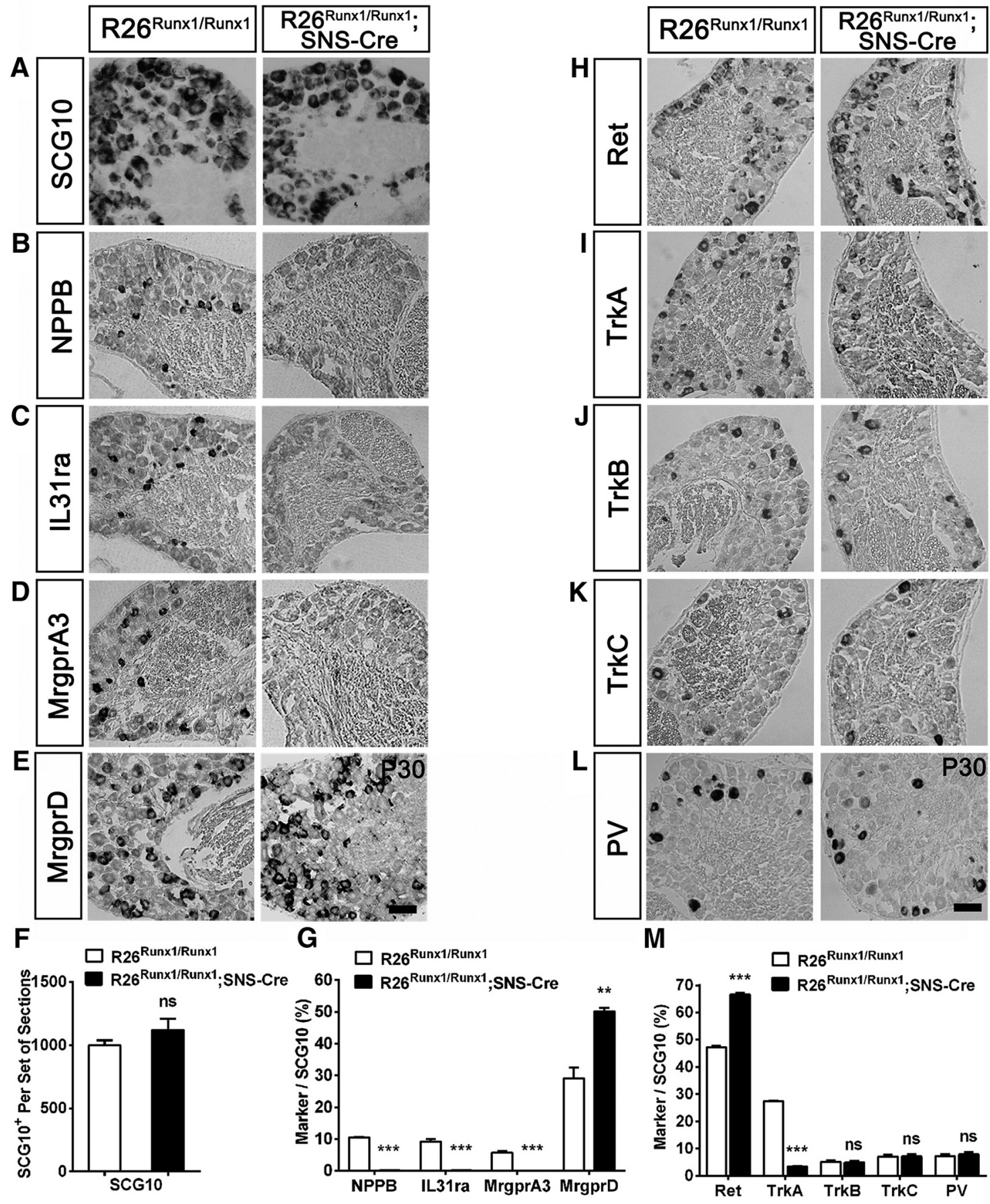

Figure 5. Complete loss of NP3 and NP2 pruriceptors in DRG with exogenous Runx1 expression driven from both Rosa 26 alleles. $A-M$, ISH with indicated probes on sections through L4 or L5 lumbar DRG from $R 26^{\text {Runx } 1 / R u n x 1} ;$;SNS-Cre and $R 26^{\text {Runx } x / R u n x 1}$ control mice $(\boldsymbol{A}-\boldsymbol{E}, \boldsymbol{H}-\boldsymbol{L})$ and quantification of positive cells $(\boldsymbol{F}, \boldsymbol{G}, \boldsymbol{M})$ showed comparable total numbers of DRG neurons $(\boldsymbol{A}, \boldsymbol{F})$, a complete loss of NP2 and NP3 neurons $(\boldsymbol{B}-\boldsymbol{D}, \boldsymbol{G})$, as well as an increase in MrgprD-expressing neurons $(\boldsymbol{E}, \boldsymbol{G})$ when exogenous Runx 1 expression was introduced in both Rosa26 alleles. As expected,

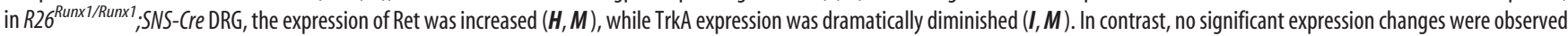
for TrkB, TrkC, and PV $(J-M)$, suggesting that the development of myelinated DRG neurons was largely unaffected in R26 $6^{\text {Runx } 1 / \text { Runx } 1 \text {; }}$;SNS-Cre mice. Scale bars, $100 \mu \mathrm{m}$. Error bars represent the SEM. Significant differences were determined by using the Student's $t$ test: ${ }^{* *} p<0.01,{ }^{* * *} p<0.001$. ns, Not significant.

We further analyzed mice in which exogenous Runxl was introduced into both Rosa26 alleles, referred to as $R 26^{\text {Runx } x 1 / R u n x 1}$; SNS-Cre mice. Again, the total number of neurons per set of L4 DRG sections remained comparable between $R 26^{\text {Runx } 1 / R u n x l}$ mice $\left(1000 \pm 38\right.$ neurons) and $R 26^{\text {Runxl/Runxl }} ;$ SNS-Cre mice (1120 \pm 88 neurons; $n=3$ for each group; $p=0.28$; Fig. $5 A, F)$. Strikingly, the expression of NPPB, IL-31ra, and MrgprA3 was virtually completely lost (Fig. $5 B-D, G$ ). Meanwhile, the proportion of
$\mathrm{MrgprD}^{+}$neurons in lumbar DRG was increased to $50.1 \pm 1.1 \%$ in $R 26^{\text {Runxl/Runxl }}$;SNS-Cre mice, and this percentage is significantly larger than that in $R 26^{\text {Runx } 1 / R u n x l}$ control mice $(29.1 \pm$ $3.3 \% ; n=3 ; p=0.0037$; Fig. $5 E, G)$ or in $R 26^{\text {Runx } 1 /+}$;SNS-Cre heterozygous mice $(41.1 \pm 0.3 \% ; n=4 ; p=0.012)$. The receptor tyrosine kinase Ret is expressed in $\mathrm{MrgprD}^{+}$and other Runx1-dependent neurons (Chen et al., 2006), and the percentage of DRG neurons expressing Ret was also increased, from 

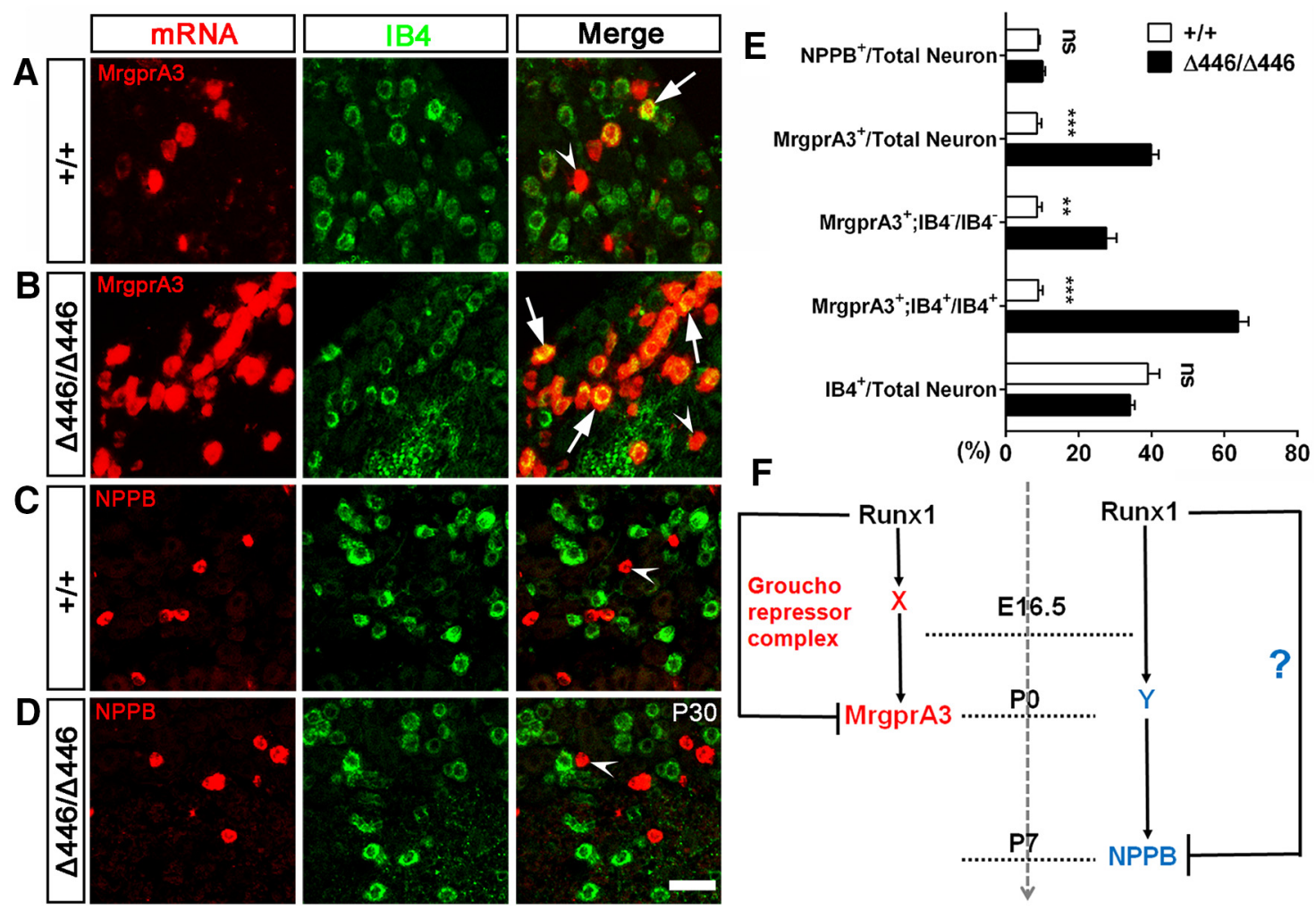

Figure 6. Differential impact on NP2 versus NP3 markers following the deletion of Runx1 C-terminal repression domain. $A-D$, ISH with MrgprA3 $(A, B)$ or NPPB $(C, D)$ probes combined with IB4 staining was performed on DRG sections from P30 $\Delta 446 / \Delta 446$ and wild-type control mice. Arrows indicate MrgprA3 ${ }^{+}$; $B 4^{+}{ }^{+}$neurons. Sunken arrowheads indicate cells with single ISH signals. Scale bar, $50 \mu \mathrm{m}$. E, Quantitative analysis showed the expansion of MrgprA3 expression in both IB4 ${ }^{+}$and IB4 ${ }^{-}$populations, as well as intact NPPB expression, in $\triangle 446 / \Delta 446$ DRG in which the C-terminal Groucho-interacting repression domain of Runx1 was removed. Significant differences were determined by using a Student'st test: ${ }^{* *} p<0.01$, ${ }^{* * *} p<0.001$. ns, Not significant. Error bars represent the SEM. $\boldsymbol{F}$, Schematic suggests different control modes used by Runx1 in regulating the development of MrgprA3-expressing NP2 versus NPPB-expressing NP3 neurons.

$47.2 \pm 0.6 \%$ in $R 26^{\text {Runxl/Runx } 1}$ control mice to $66.6 \pm 0.6 \%$ in $R 26^{\text {Runx } 1 / \text { Runxl }}$;SNS-Cre mice $(n=3 ; p<0.0001$; Fig. 5 H,M). We reported previously that Runxl can suppress the expression of the nerve growth factor receptor TrkA (Chen et al., 2006), and consistently the percentage of DRG neurons expressing TrkA was decreased, from $27.4 \pm 0.2 \%$ in $R 26^{\text {Runxl/Runx } 1}$ control mice to $3.3 \pm 0.2 \%$ in R26 Runxl/Runxl $;$ SNS-Cre mice $(n=3 ; p<0.0001$; Fig. $5 I, M)$, analogous to the situation when ectopic Runx1 expression is driven from the Tau promoter (Abdel Samad et al., 2010). The net loss of TrkA ${ }^{+}$neurons $(27.4 \%-3.3 \%=24.1 \%)$ nearly matches the net increase in $\mathrm{MrgprD}^{+}$neurons $(50.1 \%-$ $29.1 \%=21.0 \%)$ or Ret $^{+}$neurons $(66.6 \%-47.2 \%=19.4 \%)$, suggesting the possibility that a subset of $\operatorname{TrkA}^{+}$neurons had been converted into $\mathrm{MrgprD}^{+}$neurons. In contrast, no significant changes in the expression of $\operatorname{TrkB}$ (the receptor of the brain-derived neurotrophic factor; control mice, $5.2 \pm 0.4 \%$; R26 ${ }^{\text {Runx } 1 / R u n x 1}$;SNS-Cre mice, $4.9 \pm 0.6 \% ; n=3 ; p=0.70$; Fig. $5 J, M$ ), TrkC (the receptor of neurotrophin-3; control mice, $7.1 \pm 0.6 \% ; R 26^{\text {Runx } 1 / \text { Runx } 1} ;$ SNS-Cre mice, $7.1 \pm 1.0 \% ; n=3 ; p=$ 0.977; Fig. $5 K, M$ ), and parvalbumin (PV; control mice, $7.1 \pm$ $0.8 \% ; R 26^{\text {Runx } x / \text { Runxl }} ;$ SNS-Cre mice, $7.9 \pm 0.8 \% ; n=3 ; p=0.46$; Fig. $5 L, M)$ were observed between $R 26^{\text {Runxl/Runxl }} ;$ SNS-Cre and $R 26^{\text {Runxl/Runxl }}$ control mice.

Altogether, these results suggest that while early Runx1 activity is required to establish a competent state for later activation of NP2 and NP3 neuron markers, as indicated by their loss in Run $x 1^{F / F}$;Wnt1-Cre CKO mice, at later stages Runx1 itself switches to become a repressor (genetically), and Runxl downregulation becomes a prerequisite for the proper development of NP2 and
NP3 pruriceptors. In $R 26^{\text {Runxl/Runxl }}$;SNS-Cre mice in which Runx1 expression becomes constitutive, the loss of MrgprA3 ${ }^{+}$ $\mathrm{NP} 2$ and $\mathrm{NPPB}^{+} \mathrm{NP} 3$ neurons is accompanied by an increase in $\mathrm{MrgprD}^{+} \mathrm{NP1}$ neurons, although it remains to be determined whether the prospective NP2 and NP3 neurons, or other DRG neurons, are converted into $\mathrm{MrgprD}^{+}$neurons.

With marked reduction in the expression of NP2 and NP3 markers, we next assessed how $R 26^{\text {Runxl/+ }}$;SNS-Cre mice responded to different pruritogens. We found that, compared with $R 26^{\text {Runxl/+ }}$ control littermates, $R 26^{\text {Runxl/+ }}$;SNS-Cre mutant mice showed a significant reduction in scratching bouts evoked by nape injection of Compound 48/80 (control mice, $343 \pm 42$ bouts; mutants, $91 \pm 13$ bouts; $n=4$ for both groups; $p=0.0012$; Fig. $4 K$ ), CQ (control mice, $275 \pm 19$ bouts; mutants, $107 \pm 19$ bouts; $n=4$ for both groups; $p=0.0008$; Fig. $4 L$ ), IL-31 (control mice, $201 \pm 35$ bouts; mutants, $29 \pm 2$ bouts; $n=4$ for both groups; $p=0.0025$; Fig. $4 N$ ), or LTD4 (control mice, $125 \pm 24$ bouts; mutants, $29 \pm 15$ bouts; $n=5$ for both groups; $p=0.0009$; Fig. 4O). In contrast, cheek injection of $\beta$-alanine evoked scratching bouts in $R 26^{\text {Runx1/+}} ;$ SNS-Cre mice ( $79 \pm 8$ bouts), which is comparable to that in $R 26^{\text {Runxl/+ }}$ littermates ( $79 \pm 15$ bouts; $n=$ 5 for both groups; $p=0.98$; Fig. $4 M$ ), suggesting that the increase in MrgprD expression in $R 26^{\text {Runxl/+ }}$;SNS-Cre mice is insufficient to cause an augmentation in $\beta$-alanine-evoked itching responses.

Differential impact on NP2 versus NP3 markers following deletion of Runx1 C-terminal repression domain

The above studies showed that a dynamic change in Runx1 expression and activity is crucial for the proper development of NP2 


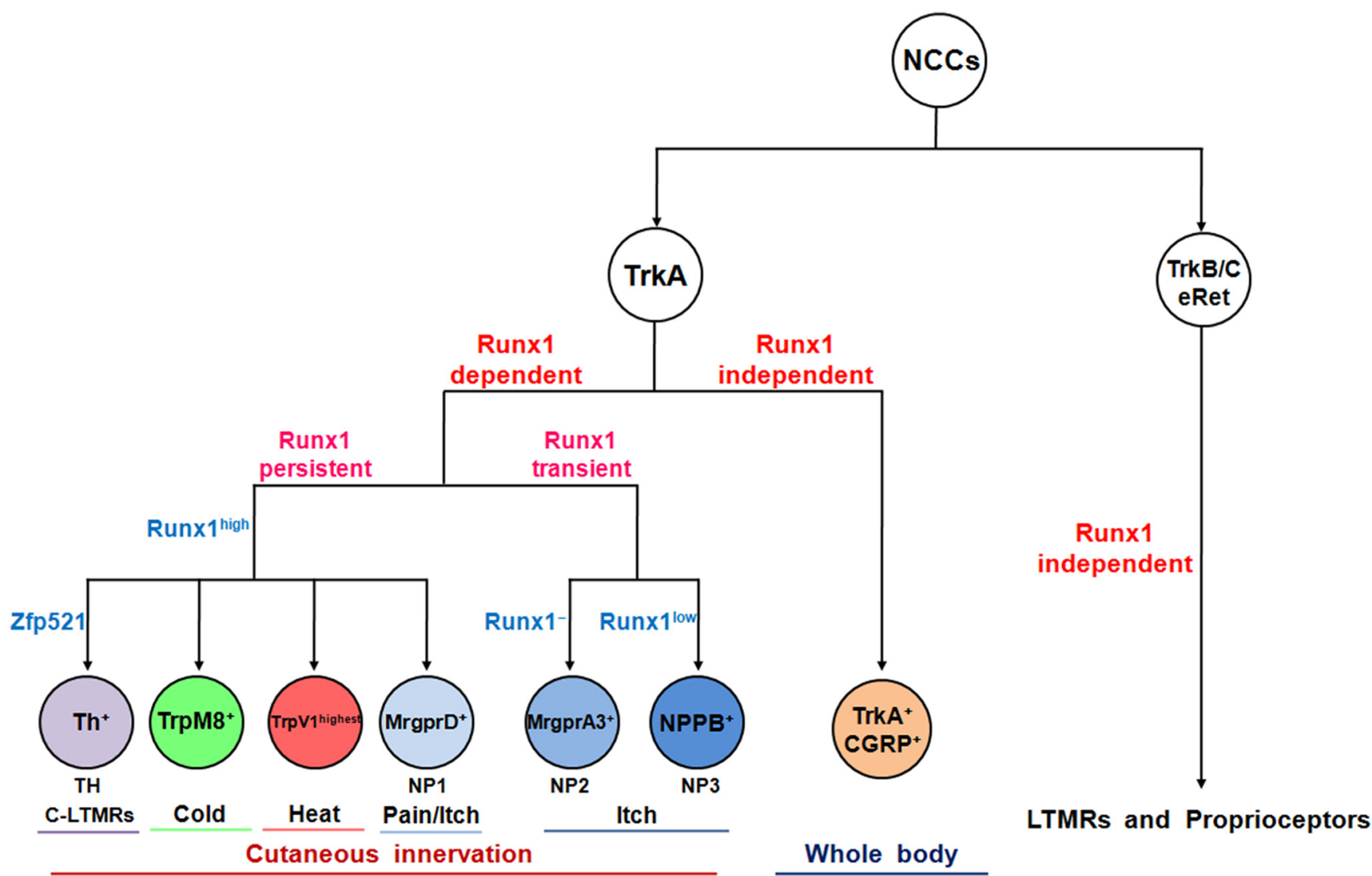

Figure 7. Hierarchical control of somatic sensory neuron development. The transcription factor Runx1 executes a master role in the development of TrkA lineage sensory neurons, as reflected by anatomical and functional subdivision of these neurons.

and NP3 pruriceptors, with Runx1 switching from an activator at an early stage to a genetic repressor at late stages. We reported previously that the C-terminal repression domain of Runx1, which binds to the Groucho repressor complex (Durst and Hiebert, 2004; Nishimura et al., 2004), is necessary for Runx1mediated suppression of MrgprA3 (Liu et al., 2008). Indeed, in homozygous $\Delta 446 / \Delta 446$ mice in which the C-terminal repression domain VWRPY is deleted, MrgprA3 expression was dramatically expanded (Fig. 6A,B). Within IB4 ${ }^{+}$neurons of lumbar DRG, the percentage of MrgprA3 ${ }^{+}$neurons was increased from $9.0 \pm 1.2 \%$ in wild-type control mice to $63.7 \pm 2.9 \%$ in $\Delta 446 /$ $\Delta 446$ mice ( $n=3$ for each group; $p=0.00006$; Fig. $6 E$ ). Expansion in IB4 ${ }^{-}$neurons was also observed, from $8.6 \pm 1.3 \%$ in control mice to $27.6 \pm 2.8 \%$ in $\Delta 446 / \Delta 446$ mice $(n=3$ for each group; $p=0.0034$; Fig. $6 E$ ). In contrast, no obvious expansion of $\mathrm{NPPB}$ was observed (control mice, $9.0 \pm 0.3 \% ; \Delta 446 / \Delta 446$ mice, $10.1 \pm 0.8 \% ; n=3$ for each group; $p=0.27$; Fig. $6 C-E$ ), suggesting distinct modes by Runx1 in controlling molecular features associated with NP2 versus NP3 pruriceptors (Fig. $6 F$ ).

\section{Discussion}

Runx1 coordinates pruriceptor development

In this study, we showed that Runxl plays a pivotal role in the development of NP3 neurons, as indicated by the requirement of this transcription factor for the expression of a cohort of NP3specific markers, including NPPB, IL-31ra, Osmr, Cysltr2, Npy2r, Nts, and Sst. Runx1 is also necessary for the development of $\mathrm{MrgprD}^{+} \mathrm{NP} 1$ neurons and MrgprA3 ${ }^{+} \mathrm{NP} 2$ neurons (Chen et al., 2006; Liu et al., 2008). Several studies show that NP2 cells and NPPB expressed in NP3 cells mediate itch evoked by most known pruritogens, including histamine-dependent and histamine-independent itch, and NP1 neurons mediate itch evoked by a more specific form of pruritogen, $\beta$-alanine (Liu et al., 2009, 2012; Han et al., 2013; Mishra and Hoon, 2013; Stantcheva et al., 2016). Recently, it was reported that DRG neurons marked by Sst-Cre, which represent a subset of $\mathrm{NPPB}^{+} / \mathrm{SST}^{+} \mathrm{NP} 3$ neurons (data not shown), led to attenuated itching responses evoked by IL-31 and serotonin (Stantcheva et al., 2016), further supporting an essential role of NP3 cells in mediating itch. Thus, Runx1 coordinates the development of these molecularly defined pruriceptors. Consistently, both acute chemical itch and chronic allergic itch are greatly attenuated or abolished following the loss of Runx1 expression.

Our studies suggest an incoherent feedforward control mechanism that can be generally applied to pruriceptor development, in which Runx1 has two opposing branches of activity. For the positive branch, Runx1 operates at early developmental stages to establish unknown downstream events (Fig. 6F, X for NP2 and Y for NP3), which is necessary for NP2/3 specification. For the negative branch, Runx1 itself serves as a genetic repressor that suppresses molecular features associated with NP2/3 pruriceptors. The repressor branch is apparently dominant; as a result, once the positive events " $\mathrm{X}$ " and "Y" are established, Runx1 downregulation becomes a prerequisite for the emergence of molecular features belonging to NP2/3 neurons. Accordingly, both Runx1 knockout at an early developmental stage and a genetic prevention of Runxl downregulation at late stages lead to the impairment of NP2/3 neuron development.

Despite the shared incoherent feedforward control mechanisms, there is a notable difference regarding how Runxl controls 
the development of NP2 versus NP3 pruriceptors. First, the timing of Runx1 activity in these two populations is different, with NP2 neurons requiring Runx1 before E16.5 and NP3 neurons requiring Runx1 beyond E16.5. Second, C-terminal Grouchointeracting repression domain of Runxl is necessary to restrict MrgprA3 expression to NP2 cells, as suggested by the remarkable expansion of MrgprA3 expression in $\Delta 446 / \Delta 446$ mice in which this repression domain is deleted. In contrast, no expansion of the NP3 neuron marker NPPB is observed in $\Delta 446 / \Delta 446$ mice. There are two possible interpretations for the lack of NPPB expansion. Since Runxl alone is insufficient to activate all Runx1-dependent genes (based on nonoverlapped expression of many Runx1dependent genes), one possibility is that only prospective NP3 neurons contain the necessary cofactors for the expression of NP3 neuron markers; as a result, removal of the C-terminal repression domain alone is insufficient for other DRG neurons to turn on NP3 markers. Alternatively, Runx1 may use different repression domains (Durst and Hiebert, 2004; Telfer et al., 2004) or activate an unknown downstream transcriptional repressor to suppress NP3 markers. It should be noted that while MrgprA3 ${ }^{+}$ neurons innervate the epidermis within the hairy skin (Han et al., 2013), $\mathrm{NPPB}^{+}$NP3 neurons innervate the border area between dermis and epidermis in both hairy and glabrous skin (Stantcheva et al., 2016), raising the possibility that the segregation of NP2 versus NP3 pruriceptors might be controlled by signals derived from different target cells.

Our studies raise a major unsolved question about itch information transmission. Although an earlier study (Mishra and Hoon, 2013) highlighted the coexpression of NPPB with "MrgprA," several other studies have demonstrated nonoverlapped expression between MrgprA3 and NPPB (Usoskin et al., 2015; Li et al., 2016). Nonetheless, either ablation of MrgprA3 neurons (Han et al., 2013) or removal of the NPPB gene (Mishra and Hoon, 2013) leads to profound deficits in scratching responses evoked by a common set of pruritogens. Thus, transmitters released from two nonoverlapped pruriceptors, NP2 and NP3, may somehow act in an integrative manner to transmit itch information in the spinal cord.

\section{Hierarchical developmental organization of somatic sensory neurons}

Our developmental studies provide a hierarchical control mechanism in specifying distinct populations of DRG neurons (Fig. 7). Somatic sensory neurons are formed mainly during two waves (Frank and Sanes, 1991). The early wave produces proprioceptors and myelinated low-threshold mechanoreceptors (LTMRs), whose genesis is dependent mainly on proneural gene neurogenin 2 and minorly on neurogenin 1 (Ma et al., 1999). The late waves produce most of the neurons of TrkA lineage, which coexpress Runx1 at E12.5-E14.5 (Ma et al., 1999; Chen et al., 2006), although a small subset of thinly myelinated TrkA lineage neurons is produced during the early wave (Bachy et al., 2011). The dynamic change in Runx1 expression during neonatal and postnatal development then leads to a broad segregation of TrkA lineage neurons into two groups (Chen et al., 2006; Abdel Samad et al., 2010; Yang et al., 2013). The first group switches off Runx1 and retains TrkA, giving rise to "classic" peptidergic sensory neurons that express neuropeptides calcitonin gene-related peptide (CGRP) and/or substance P (Chen et al., 2006; Usoskin et al., 2015). Development of most of these peptidergic neurons is not only independent of Runx1 but also requires Runx1 extinguishment during prenatal and postnatal stages since Runx1 acts genetically as a repressor of TrkA, CGRP, and hundreds of genes expressed in these neurons (Chen et al., 2006; Abdel Samad et al., 2010; Yang et al., 2013). The second group of TrkA lineage neurons includes $\mathrm{MrgprD}^{+} \mathrm{NP} 1, \mathrm{MrgprA3}^{+} \mathrm{NP} 2, \mathrm{NPPB}^{+} \mathrm{NP} 3$, $\mathrm{TH}^{+}$C-LTMRs, TRPM8 ${ }^{+}$cold-sensing neurons, and warm/ heat-sensing neurons with the highest TRPV1 expression (representing $\sim 10 \%$ of total TRPV ${ }^{+}$neurons), all of which depend on Runx1 for proper development (see above; Zylka et al., 2005; Chen et al., 2006; Li et al., 2011; Delfini et al., 2013; Han et al., 2013; Knowlton et al., 2013; Lou et al., 2013; Mishra and Hoon, 2013; Pogorzala et al., 2013; Usoskin et al., 2015). These Runx1dependent neurons are then divided into two subgroups (Fig. 7). One expresses Runxl persistently, including MrgprD $^{+} \mathrm{NP1}$ neurons, $\mathrm{TH}^{+}$C-LTMRs, cold-sensing TRPM8 ${ }^{+}$neurons, and warm-sensing TRPV $1{ }^{\text {highest }}$ neurons, and a further segregation of $\mathrm{MrgprD}^{+}$versus $\mathrm{TH}^{+}$neurons is achieved by selective expression of the zinc finger protein 521 (Zfp521) in TH neurons (Chen et al., 2006; Lou et al., 2013; Lou et al., 2015). The other Runx1dependent subgroup includes MrgprA3 ${ }^{+} \mathrm{NP} 2$ and $\mathrm{NPPB}^{+} \mathrm{NP} 3$ pruriceptors, the development of which requires both early Runx1 activity and subsequent Runxl downregulation (see above; Liu et al., 2008). Since Runxl acts to activate Ret and to suppress TrkA and CGRP, Runx1-persistent neurons, such as $\mathrm{MrgprD}^{+}$neurons, express Ret but not TrkA/CGRP (Chen et al., 2006), whereas Runx1 downregulation in NP2 and NP3 neurons might explain why these neurons express low levels of Ret and also display detectable TrkA and CGRP expression (Han et al., 2013; Usoskin et al., 2015; Li et al., 2016; Stantcheva et al., 2016).

This hierarchical organization also reflects anatomical and/or functional subdivision of TrkA lineage somatosensory neurons (Fig. 7). First, the broad segregation of Runx1-depenent and Runx1-independent subpopulations correlates with a bodily organization of sensory afferent innervation. Runx1-dependent neurons, including NP1, NP2, NP3, $\mathrm{TH}^{+}, \mathrm{TRPM}^{+}$, and TRPV $1{ }^{\text {highest }}$ neurons, all innervate predominantly, if not exclusively, superficial tissues derived from the ectoderm or in regions right next to ectodermal tissues, such as epidermis, hair follicles, and the border region between epidermis and dermis (Zylka et al., 2005; Christianson et al., 2006; Takashima et al., 2007; Li et al., 2011; Malin et al., 2011; Han et al., 2013; Lou et al., 2013; Yang et al., 2013; Stantcheva et al., 2016). In contrast, Runx1-independent $\mathrm{TrkA}^{+} / \mathrm{CGRP}^{+}$neurons innervate throughout the body, with particularly high representation for neurons innervating deep mesodermal and endodermal tissues (McMahon et al., 1994; Bennett et al., 1996; Castañeda-Corral et al., 2011; Yang et al., 2013). Second, among six Runx1-dependent subtypes, the Runx1-persistent group (MrgprD ${ }^{+} \mathrm{NP1}, \mathrm{TH}^{+}, \mathrm{TRPM}^{+}$, and TRPV $\left.1^{\text {highest }}\right)$ is required to transmit mechanical and thermal sensory information (even though NP1 also play a minor role in sensing itch evoked only by $\beta$-alanine; Cavanaugh et al., 2009; Rau et al., 2009; Seal et al., 2009; Liu et al., 2012; Knowlton et al., 2013; Pogorzala et al., 2013; François et al., 2015), whereas the Runx1-transient group (NP2 and NP3) acts as pruriceptors (Han et al., 2013; Mishra and Hoon, 2013; Fig. 7). We hypothesize that persistent versus transient expression of Runxl might partially provide a developmental solution for different DRG neurons to be connected to spinal neurons that transmit different sensory modalities, such as pain versus itch.

\section{References}

Abdel Samad O, Liu Y, Yang FC, Kramer I, Arber S, Ma Q (2010) Characterization of two Runxl-dependent nociceptor differentiation programs necessary for inflammatory versus neuropathic pain. Mol Pain 6:45. CrossRef Medline 
Agarwal N, Offermanns S, Kuner R (2004) Conditional gene deletion in primary nociceptive neurons of trigeminal ganglia and dorsal root ganglia. Genesis 38:122-129. CrossRef Medline

Arcourt A, Gorham L, Dhandapani R, Prato V, Taberner FJ, Wende H, Gangadharan V, Birchmeier C, Heppenstall PA, Lechner SG (2017) Touch receptor-derived sensory information alleviates acute pain signaling and fine-tunes nociceptive reflex coordination. Neuron 93:179-193. CrossRef Medline

Bachy I, Franck MC, Li L, Abdo H, Pattyn A, Ernfors P (2011) The transcription factor Cux2 marks development of an A-delta sublineage of TrkA sensory neurons. Dev Biol 360:77-86. CrossRef Medline

Bennett DL, Dmietrieva N, Priestley JV, Clary D, McMahon SB (1996) trkA, CGRP and IB4 expression in retrogradely labelled cutaneous and visceral primary sensory neurones in the rat. Neurosci Lett 206:33-36. CrossRef Medline

Castañeda-Corral G, Jimenez-Andrade JM, Bloom AP, Taylor RN, Mantyh WG, Kaczmarska MJ, Ghilardi JR, Mantyh PW (2011) The majority of myelinated and unmyelinated sensory nerve fibers that innervate bone express the tropomyosin receptor kinase A. Neuroscience 178:196-207. CrossRef Medline

Cavanaugh DJ, Lee H, Lo L, Shields SD, Zylka MJ, Basbaum AI, Anderson DJ (2009) Distinct subsets of unmyelinated primary sensory fibers mediate behavioral responses to noxious thermal and mechanical stimuli. Proc Natl Acad Sci U S A 106:9075-9080. CrossRef Medline

Chen CL, Broom DC, Liu Y, de Nooij JC, Li Z, Cen C, Samad OA, Jessell TM, Woolf CJ, Ma Q (2006) Runx1 determines nociceptive sensory neuron phenotype and is required for thermal and neuropathic pain. Neuron 49:365-377. CrossRef Medline

Chiu IM, Barrett LB, Williams EK, Strochlic DE, Lee S, Weyer AD, Lou S, Bryman GS, Roberson DP, Ghasemlou N, Piccoli C, Ahat E, Wang V, Cobos EJ, Stucky CL, Ma Q, Liberles SD, Woolf CJ (2014) Transcriptional profiling at whole population and single cell levels reveals somatosensory neuron molecular diversity. Elife 3:e04660. CrossRef Medline

Christianson JA, Traub RJ, Davis BM (2006) Differences in spinal distribution and neurochemical phenotype of colonic afferents in mouse and rat. J Comp Neurol 494:246-259. CrossRef Medline

Delfini MC, Mantilleri A, Gaillard S, Hao J, Reynders A, Malapert P, Alonso S, François A, Barrere C, Seal R, Landry M, Eschallier A, Alloui A, Bourinet E, Delmas P, Le Feuvre Y, Moqrich A (2013) TAFA4, a chemokine-like protein, modulates injury-induced mechanical and chemical pain hypersensitivity in mice. Cell Rep 5:378-388. CrossRef Medline

Dillon SR, Sprecher C, Hammond A, Bilsborough J, Rosenfeld-Franklin M, Presnell SR, Haugen HS, Maurer M, Harder B, Johnston J, Bort S, Mudri S, Kuijper JL, Bukowski T, Shea P, Dong DL, Dasovich M, Grant FJ, Lockwood L, Levin SD, et al (2004) Interleukin 31, a cytokine produced by activated T cells, induces dermatitis in mice. Nat Immunol 5:752-760. CrossRef Medline

Durst KL, Hiebert SW (2004) Role of RUNX family members in transcriptional repression and gene silencing. Oncogene 23:4220-4224. CrossRef Medline

François A, Schuetter N, Laffray S, Sanguesa J, Pizzoccaro A, Dubel S, Mantilleri A, Nargeot J, Noel J, Wood JN, Moqrich A, Pongs O, Bourinet E (2015) The low-threshold calcium channel Cav3.2 determines lowthreshold mechanoreceptor function. Cell Rep 10:370-382. CrossRef Medline

Frank E, Sanes JR (1991) Lineage of neurons and glia in chick dorsal root ganglia: analysis in vivo with a recombinant retrovirus. Development 111:895-908. Medline

Gao YJ, Ji RR (2009) c-Fos and pERK, which is a better marker for neuronal activation and central sensitization after noxious stimulation and tissue injury? Open Pain J 2:11-17. CrossRef Medline

Growney JD, Shigematsu H, Li Z, Lee BH, Adelsperger J, Rowan R, Curley DP, Kutok JL, Akashi K, Williams IR, Speck NA, Gilliland DG (2005) Loss of Runx1 perturbs adult hematopoiesis and is associated with a myeloproliferative phenotype. Blood 106:494-504. CrossRef Medline

Han L, Ma C, Liu Q, Weng HJ, Cui Y, Tang Z, Kim Y, Nie H, Qu L, Patel KN, Li Z, McNeil B, He S, Guan Y, Xiao B, Lamotte RH, Dong X (2013) A subpopulation of nociceptors specifically linked to itch. Nat Neurosci 16:174-182. CrossRef Medline

Hunt SP, Pini A, Evan G (1987) Induction of c-fos-like protein in spinal cord neurons following sensory stimulation. Nature 328:632-634. CrossRef Medline
Imamachi N, Park GH, Lee H, Anderson DJ, Simon MI, Basbaum AI, Han SK (2009) TRPV1-expressing primary afferents generate behavioral responses to pruritogens via multiple mechanisms. Proc Natl Acad Sci U S A 106: 11330-11335. CrossRef Medline

Jiang X, Rowitch DH, Soriano P, McMahon AP, Sucov HM (2000) Fate of the mammalian cardiac neural crest. Development 127:1607-1616. Medline

Knowlton WM, Palkar R, Lippoldt EK, McCoy DD, Baluch F, Chen J, McKemy DD (2013) A sensory-labeled line for cold: TRPM8-expressing sensory neurons define the cellular basis for cold, cold pain, and coolingmediated analgesia. J Neurosci 33:2837-2848. CrossRef Medline

Krajnik M, Zylicz Z (2001) Understanding pruritus in systemic disease. J Pain Symptom Manage 21:151-168. CrossRef Medline

Li CL, Li KC, Wu D, Chen Y, Luo H, Zhao JR, Wang SS, Sun MM, Lu YJ, Zhong YQ, Hu XY, Hou R, Zhou BB, Bao L, Xiao HS, Zhang X (2016) Somatosensory neuron types identified by high-coverage single-cell RNA-sequencing and functional heterogeneity. Cell Res 26:83-102. CrossRef Medline

Li L, Rutlin M, Abraira VE, Cassidy C, Kus L, Gong S, Jankowski MP, Luo W, Heintz N, Koerber HR, Woodbury CJ, Ginty DD (2011) The functional organization of cutaneous low-threshold mechanosensory neurons. Cell 147:1615-1627. CrossRef Medline

Liu Q, Tang Z, Surdenikova L, Kim S, Patel KN, Kim A, Ru F, Guan Y, Weng HJ, Geng Y, Undem BJ, Kollarik M, Chen ZF, Anderson DJ, Dong X (2009) Sensory neuron-specific GPCR Mrgprs are itch receptors mediating chloroquine-induced pruritus. Cell 139:1353-1365. CrossRef Medline

Liu Q, Sikand P, Ma C, Tang Z, Han L, Li Z, Sun S, LaMotte RH, Dong X (2012) Mechanisms of itch evoked by beta-alanine. J Neurosci 32:1453214537. CrossRef Medline

Liu Y, Yang FC, Okuda T, Dong X, Zylka MJ, Chen CL, Anderson DJ, Kuner R, Ma Q (2008) Mechanisms of compartmentalized expression of Mrg class G-protein-coupled sensory receptors. J Neurosci 28:125-132. CrossRef Medline

Liu Y, Abdel Samad O, Zhang L, Duan B, Tong Q, Lopes C, Ji RR, Lowell BB, Ma Q (2010) VGLUT2-dependent glutamate release from nociceptors is required to sense pain and suppress itch. Neuron 68:543-556. CrossRef Medline

Lou S, Duan B, Vong L, Lowell BB, Ma Q (2013) Runxl controls terminal morphology and mechanosensitivity of VGLUT3-expressing C-mechanoreceptors. J Neurosci 33:870-882. CrossRef Medline

Lou S, Pan X, Huang T, Duan B, Yang FC, Yang J, Xiong M, Liu Y, Ma Q (2015) Incoherent feedforward regulatory loops control segregation of C-mechanoreceptors, nociceptors, and pruriceptors. J Neurosci 35:53175329. CrossRef Medline

Ma Q, Fode C, Guillemot F, Anderson DJ (1999) Neurogenin1 and neurogenin2 control two distinct waves of neurogenesis in developing dorsal root ganglia. Genes Dev 13:1717-1728. CrossRef Medline

Malin S, Molliver D, Christianson JA, Schwartz ES, Cornuet P, Albers KM, Davis BM (2011) TRPV1 and TRPA1 function and modulation are target tissue-dependent. J Neurosci 31:10516-10528. CrossRef Medline

Mcmahon SB, Armanini MP, Ling LH, Phillips HS (1994) Expression and coexpression of Trk receptors in subpopulations of adult primary sensory neurons projecting to identified peripheral targets. Neuron 12:11611171. CrossRef Medline

Mishra SK, Hoon MA (2013) The cells and circuitry for itch responses in mice. Science 340:968-971. CrossRef Medline

Nishimura M, Fukushima-Nakase Y, Fujita Y, Nakao M, Toda S, Kitamura N, Abe T, Okuda T (2004) VWRPY motif-dependent and -independent roles of AML1/Runx1 transcription factor in murine hematopoietic development. Blood 103:562-570. CrossRef Medline

Patel TD, Jackman A, Rice FL, Kucera J, Snider WD (2000) Development of sensory neurons in the absence of NGF/TrkA signaling in vivo. Neuron 25:345-357. CrossRef Medline

Pogorzala LA, Mishra SK, Hoon MA (2013) The cellular code for mammalian thermosensation. J Neurosci 33:5533-5541. CrossRef Medline

Rau KK, McIlwrath SL, Wang H, Lawson JJ, Jankowski MP, Zylka MJ, Anderson DJ, Koerber HR (2009) Mrgprd enhances excitability in specific populations of cutaneous murine polymodal nociceptors. J Neuroscience 29:8612-8619. CrossRef Medline

Seal RP, Wang X, Guan Y, Raja SN, Woodbury CJ, Basbaum AI, Edwards RH 
(2009) Injury-induced mechanical hypersensitivity requires C-low threshold mechanoreceptors. Nature 462:651-655. CrossRef Medline

Shimada SG, LaMotte RH (2008) Behavioral differentiation between itch and pain in mouse. Pain 139:681-687. CrossRef Medline

Stantcheva KK, Iovino L, Dhandapani R, Martinez C, Castaldi L, Nocchi L, Perlas E, Portulano C, Pesaresi M, Shirlekar KS, de Castro Reis F, Paparountas T, Bilbao D, Heppenstall PA (2016) A subpopulation of itchsensing neurons marked by Ret and somatostatin expression. EMBO Rep 17:585-600. CrossRef Medline

Sugimoto Y, Umakoshi K, Nojiri N, Kamei C (1998) Effects of histamine H1 receptor antagonists on compound 48/80-induced scratching behavior in mice. Eur J Pharmacol 351:1-5. CrossRef Medline

Takashima Y, Daniels RL, Knowlton W, Teng J, Liman ER, McKemy DD (2007) Diversity in the neural circuitry of cold sensing revealed by genetic axonal labeling of transient receptor potential melastatin 8 neurons. J Neurosci 27:14147-14157. CrossRef Medline

Taylor-Clark TE, Nassenstein C, Undem BJ (2008) Leukotriene D4 increases the excitability of capsaicin-sensitive nasal sensory nerves to elec- trical and chemical stimuli. Br J Pharmacol 154:1359-1368. CrossRef Medline

Telfer JC, Hedblom EE, Anderson MK, Laurent MN, Rothenberg EV (2004) Localization of the domains in Runx transcription factors required for the repression of CD4 in thymocytes. J Immunol 172:4359-4370. CrossRef Medline

Usoskin D, Furlan A, Islam S, Abdo H, Lönnerberg P, Lou D, Hjerling-Leffler J, Haeggström J, Kharchenko O, Kharchenko PV, Linnarsson S, Ernfors P (2015) Unbiased classification of sensory neuron types by large-scale single-cell RNA sequencing. Nat Neurosci 18:145-153. CrossRef Medline

Yang FC, Tan T, Huang T, Christianson J, Samad OA, Liu Y, Roberson D, Davis BM, Ma Q (2013) Genetic control of the segregation of painrelated sensory neurons innervating the cutaneous versus deep tissues. Cell Rep 5:1353-1364. CrossRef Medline

Zylka MJ, Rice FL, Anderson DJ (2005) Topographically distinct epidermal nociceptive circuits revealed by axonal tracers targeted to Mrgprd. Neuron 45:17-25. CrossRef Medline 